\title{
Architectural Diversity of the Cuticle and Epidermis of Native and Hybrid Tomato Fruit Genotypes and the Relation to Polygalacturonase Expression
}

\author{
Cristián VELA-HINOJOSA ${ }^{1}$, Claudia BARBOSA-MARTÍNEZ ${ }^{2}$, \\ Héctor B. ESCALONA-BUENDÍA ${ }^{3}$, José Alberto MENDOZA-ESPINOZA ${ }^{4}$, \\ Ricardo LOBATO-ORTÍZ ${ }^{5}$, Juan Enrique RODRÍGUEZ-PÉREZ ${ }^{6}$, \\ Juan Manuel VILLA-HERNÁNDEZ 7 , Laura J. PÉREZ-FLORES ${ }^{7 *}$ \\ ${ }^{1}$ Universidad Autónoma Metropolitana Iztapalapa, Biotechnology PhD program, Av. San Rafael Atlixco 186, \\ Col.Vicentina, CP 09310. México D.F., Mexico; cristianvh@msn.com \\ ${ }^{2}$ Universidad Autónoma Metropolitana Iztapalapa, Departamento de Biología. Av. San Rafael Atlixco 186, \\ Col.Vicentina, CP 09310. México D.F., Mexico; clbm@xanum.uam.mx \\ ${ }^{3}$ Universidad Autónoma Metropolitana Iztapalapa, Departamento de Biotecnología. Av. San Rafael Atlixco 186, \\ Col.Vicentina, CP 09310.México D.F., Mexico; bbeb@xanum.uam.mx \\ ${ }^{4}$ Universidad Autónoma de la Ciudad de México, Colegio de Ciencias y Humanidades, Calzada Ermita Iztapalapa 4163. \\ CP 09620. México D.F., Mexico; amendozaespinoza@gmail.com \\ ${ }^{5}$ Colegio de Postgraduados, Departamento de Recursos Genéticos y Productividad, Campus Montecillo Km 36.5 Carretera México-Texcoco. \\ CP 56230. Estado de México, Mexico; rlobato@colpos.mx \\ ${ }^{6}$ Universidad Autónoma Chapingo, Departamento de Fitotecnia, Km. 38.5 Carretera México-Texcoco. CP 56230 Chapingo. \\ Estado de México, Mexico; erodriguezx@yahoo.com.mx \\ ${ }^{7}$ Universidad Autónoma Metropolitana Iztapalapa, Departamento de Ciencias de la Salud, Av. San Rafael Atlixco 186, \\ Col.Vicentina, CP 09310. México D.F., Mexico;jmvh@xanum.uam.mx; ljpf@xanum.uam.mx (*correspondingauthor)
}

\begin{abstract}
The tomato (Solanum lycopersicum L.) fruit has been widely studied because of its high consumption, nutritional value, and well-characterized genome. It also represents a good model for studying the structure and function of the cuticle, a protective film that is deposited on the surface of outer epidermal cell walls, and affects the integrity and firmness of the fruit, and, therefore, its commercialization. To evaluate the differences in their structure and function, we characterized the morphology of the cuticle and the epidermis and their relationship to firmness, brightness, weight loss, and transcript levels of polygalacturonase $(P G A)$ in four hybrid genotypes and four native genotypes of different origins, shapes, and colors. Our results show a different architecture of the epidermis and cell wall among the genotypes. Native genotypes showed irregularshaped epidermal cells and a thicker epidermis. Anticlinal pegs were also present to only one-third of the depth of the epidermal cells. The hybrid fruit surface was smoother compared to native genotypes, and it was associated with a higher level of brightness and a less weight loss. A negative correlation between firmness and $P G A$ transcript levels was found. The chartreuse yellow genotype was the firmest, and it had the lowest levels of $P G A$ expression. Meanwhile, the black genotype displayed the lowest weight loss and stem scar diameter. Our results suggest that several morphological features of the cuticle and epidermis have been modified through selection of the tomato fruit, altering quality parameters, such as weight loss and firmness.
\end{abstract}

Keywords: firmness, native and hybrid tomato fruit genotypes, cuticle, polygalacturonase, weight

\section{Introduction}

Epidermal differentiation and maintenance is considered essential for plant survival. This tissue is composed of a single layer of thick-walled cells that strongly adhere to each other to form a boundary between all plant organs and the external environment (Heredia et al., 2015). The epidermis is covered by the cuticle, a protective layer consisting of 
46

cutin and waxes that surround the primary aerial organs of all land plants. The cuticle serves different functions, such as protection against mechanical damage and pathogen invasion, water loss prevention, and filtering of potentially damaging UV light (Heredia et al., 2015). It is regarded as a special modification of the cell wall and its evolution gave plants an advantage when colonizing land, resulting in significant diversification of cuticle morphology and composition (Yeats et al., 2012; España et al., 2014). Fruit cuticles are chemically heterogenous, consisting of a matrix composed of cutin ( $40-80 \%$ weight) and a polymer composed of a network of oxygenated C16 and/or C18 fatty acids that are cross-linked by ester bonds. Its thickness can vary among species. In tomato fruit, a thickness of 0.66$4.40 \mu \mathrm{m}$ has been reported (Borowiak and Habdas, 1988; Domínguez et al., 2011).

During fruit ripening, the cell wall-modifying activity of several enzymes - mainly polygalacturonase (PGA) - alters the texture and firmness of the fruit as a result of degradation of the structural components necessary to reinforce the cell wall and the adhesion of cells (Martin and Rose, 2014).

The tomato fruit has been widely studied because of its high consumption, nutritional value, short life cycle, and well-characterized genome (Bonilla-Barrientos et al., 2014). It also represents a good system for biomechanical and morphological studies because the mechanical performance and integrity of the exocarp are of economic importance for the integrity of the fruit (Bargel and Neinhuis, 2004).

Mexico is a center for the diversification and domestication of the tomato and it offers a wide range of genotypes that have important morphological differences. Native genotypes have been produced on a small scale, both in backyard and open-air conditions. It is believed that longterm exposure to continuous environmental stresses and pathogen infections promote the development of defense mechanisms that increase plant survival. This could be useful in breeding programs aiming to improve the shelf-life and quality of the tomato (Bonilla-Barrientos et al., 2014).

The aim of this study was to characterize the morphology of the cuticle and the epidermis to evaluate variations in firmness, brightness, weight loss, and expression levels of $P G A$ in hybrid and native tomato (Solanum lycopersicum L.) genotypes of different origins, shapes, and colorations.

\section{Materials and Methods}

\section{Biologicalmaterial}

Eight tomato (Solanum lycopersicum L.) genotypes of different colors: four natives (red (accession code 15014), orange (15006-3A), yellow (15011), and purple (15440) and four hybrids (light red (H1329) light orange (H1326) chartreuse yellow (ELF5, and black (BELF8). Native genotypes were obtained from Xicontepec, Puebla, Mexico (red and yellow), San Gabriel Chilac, Puebla, Mexico (Orange) and Tehuacán, Puebla, Mexico (purple). Genotypes varied in shape and size (Fig. 1). All genotypes were grown under greenhouse conditions at $23^{\circ} \mathrm{C}( \pm 3)$ and relative humidity of $50( \pm 10)$ for 60 days in volcanic sand substrate and a nutrient solution (Steiner, 1996). The native and hybrid genotypes were cultivated in two nearby greenhouses under the same conditions - the first was located at (19०2 $\left.27^{\prime} 39^{\prime \prime} \mathrm{N}, 98^{\circ} 54^{\prime} 23^{\prime \prime} \mathrm{W}, 2295 \mathrm{MASL}\right)$ and the second was at (19०29' $21^{\prime \prime} \mathrm{N}, 98^{\circ} 52^{\prime} 25^{\prime \prime} \mathrm{W}, 2295$ MASL). Ripe fruits were selected based on a color chart developed specifically for each genotype and harvested free of mechanical damage, physical defects, pests and blemishes, and transported immediately after harvest to the Universidad Autónoma Metropolitana-Iztapalapa.

\section{Light microscopy}

Tomato fruits were sliced in sections of $1 \mathrm{~cm}^{2}$ and fixed in a formaldehyde solution $4 \% \mathrm{v} / \mathrm{v} \mathrm{pH} 6.9$ for 48 hours. Samples were dehydrated in water-ethanol-ter-butyl alcohol (TBA) in the following proportions: 50:40:10, 30:50:20, 15:50:35, 5:40:55, 0:25:75 and 0:0:100 v/v/v for five hours. Tissue sections of tomato fruit tissue were mounted in paraffin-Paraplast 50:50 w/w and cut on a manual microtome (12 $\mu \mathrm{m}$ thick). Sections were deparaffinized in two changes of xylene, washed with descending concentrations of ethanol and stained with $0.1 \% \mathrm{w} / \mathrm{v}$ safranin O solution in $95 \% \mathrm{v} / \mathrm{v}$ ethanol overnight. Samples were rinsed with tap water and dehydrated in a graded ethanol series $(50 \%, 60 \%, 70 \%, 80 \%$ v/v). Slides were stained with fast green FCF for two seconds and then rinsed with absolute grade ethanol, a clove oil solution and xylene. Microscope slides were finally mounted with resinous mounting media. $4 \mathrm{~mm}$ segments of isolated tomato epidermis were also directly observed through the microscope.

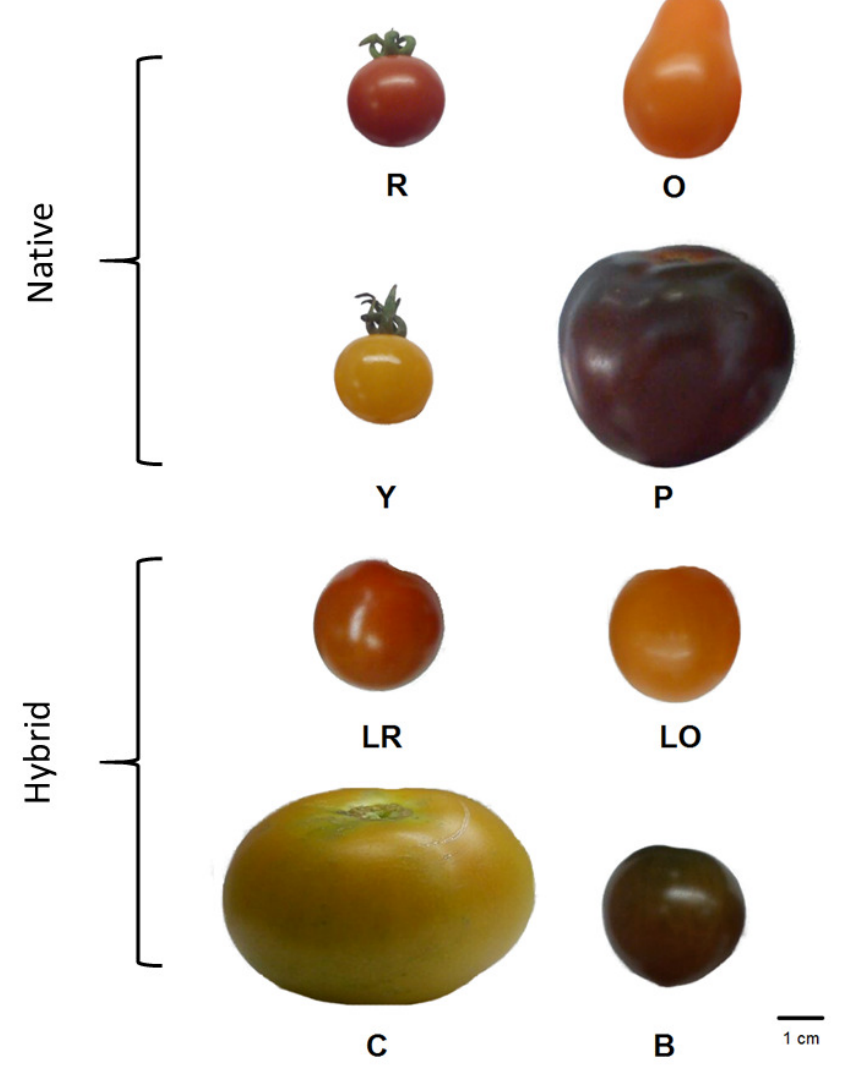

Fig. 1. Appearance of native and hybrid tomato genotypes. Native genotypes: red $(\mathrm{R})$, orange $(\mathrm{O})$, yellow $(\mathrm{Y})$, purple $(\mathrm{P})$. Hybrid genotypes: light red (LR), light orange (LO), chartreuse yellow (C) and black (B) 


\section{Scanning electron microscopy}

Tomato fruits were sliced in sections of $1 \mathrm{~cm}^{2}$ and fixed in a glutaraldehyde $2.5 \% \mathrm{v} / \mathrm{v}$ solution in $0.2 \mathrm{M}$ phosphate buffer, $\mathrm{pH} 7.4$ for 72 hours. Samples were subsequently dehydrated in a graded ethanol series and critical pointdried. Prior to SEM samples were coated with gold. Samples were observed with the scanning electron microscope JEOL model JSM-5900 LV (USA).

\section{Expression of polygalacturase ( $P G A)$}

The extraction protocol was performed according to the technique reported by Chang et al. (1993). The purity and concentration of the RNA were determined by spectrophotometry (absorbance 260/280 nm), and the integrity was verified by a $1 \% \mathrm{w} / \mathrm{v}$ agarose gel stained with ethidium bromide.

Specific oligonucleotides were designed for polygalacturonase (PGA2): (forward 5'ACAAACTTTCCATGTGAAGGAATTA, reverse 5'TATACAAAAGAGCTTCATCCTCTGAA). The transcripts of interest were amplified by RT-qPCR using the kit Express SYBR GreenER ${ }^{2 P C R}$ Supermix (ThermoFisher Scientific, USA). $1 \mu \mathrm{l}$ of RNA treated with DNase (Thermo Fisher Scientific) was loaded per tube, obtaining a final volume of $10.5 \mu \mathrm{l}$. The $18 \mathrm{~S}$ rRNA fragment was used as reference gene (forward 5'AAACGGCTACCACATCCAAG-3', reverse 5'GCCATCCCAAAGTCCAACTA-3'). The following temperature program was used: $\mathrm{RT}$ reaction at $37^{\circ} \mathrm{C}$ for 10 minutes, initial denaturation at $95^{\circ} \mathrm{C}$ for 3 minutes, $94^{\circ} \mathrm{C}$ for 30 seconds, alignment temperature of $54{ }^{\circ} \mathrm{C}$, for 20 seconds, a and final temperature of $72{ }^{\circ} \mathrm{C}$ for 30 seconds. Relative mRNA expression was calculated by $2^{-\Delta \Delta \mathrm{Ct}}$ method (Villa-Hernández et al., 2013). A value of 1 was arbitrarily assigned to the mRNA expression of red native genotype, and the relative expression of the other genotypes was calculated using this genotype as reference.

\section{Brightness}

Brightness was measured with a colorimeter ColorFlex 45/0 Konica Minolta (Tokyo, Japan).

\section{Weight loss percentage}

Three replications of ten fruits were stored at $23^{\circ} \mathrm{C}$ and $83 \pm 2 \%$ and weighed initially and at 10 days on an electric scale. The weight loss percentage was calculated via the following equation: \% Weight loss $=[(\mathrm{Wi}-\mathrm{Wf}) / \mathrm{Wi}]$ $\times 100(\mathrm{Wi}=$ initial weight, $\mathrm{Wf}=$ final weight $)$

\section{Firmness}

Firmness was measured with and without epidermis. Pressure was applied with a $7 \mathrm{~mm}$ diameter punch via a penetrometer (Effe-Gi, Milan, Italy) to determine the amount of force required to puncture the skin in Newtons $(\mathrm{N})$. The contribution of the epidermis to firmness (\%) was calculated using the following formula: firmness without epidermis $\times 100$ / firmness with epidermis.

Statistical analysis

Analysis were carried out using ANOVA + Tukey (significance level of $0.05(\alpha=0.05)$ ) using Prism 7.0
(GraphPad Software Inc., 2017). Measurements of the cuticle and epidermis were carried out with Image J software $(n=3)$. Pearson product-moment correlation coefficient was calculated, and Kolmogorov-Smirnov test was previously used to verify a normal distribution of values.

\section{Results and Discussion}

\section{Fruit surface and brightness}

A diverse epidermal architecture was observed among the tomato genotypes using light microscopy (Fig. 2). Epidermal cells of native genotypes showed a more geometric shape, as well as thicker cell walls compared to hybrid genotypes. Chloroplasts were detected in the cytoplasm of epidermal cells in the purple and black genotypes, indicating that these were not degraded during fruit ripening. When examined under scanning electron microscopy (SEM), a flat surface topology was observed in hybrid genotypes, except for the black hybrid genotype, which showed a smooth surface with small bumps. In contrast, the fruit surface of native genotypes was covered by circular-shaped clefts.

Yeats et al. (2012) studied seven wild related tomato species and found architectural and chemical differences among the fruit cuticles. A trend towards a flatter rather than undulating cuticle surface was observed in species most closely related to Solanum lycopersicum L., suggesting that cuticle morphology has a substantial effect on the surface and cuticular water conductance. The native genotypes analyzed in this study have a higher exposed surface because of their irregular topology, and, therefore, increased cuticular transpiration (Bouzo and Gariglio, 2016). Although the minimization of water loss is the main function of the cuticle it may also play a role in the appearance and texture of the fruit. Thus, it may affect key traits related to postharvest quality, such as firmness and weight loss (Lara et al., 2014).

A relationship between fruit brightness and fruit surface was also observed since hybrid fruits with a smoother surface displayed higher brightness values. Brightness values obtained in this study were as follows: light red $39.9( \pm 2.9)$, light orange $45.4( \pm 1.2)$, chartreuse yellow $49.5( \pm 2.3)$, and black $36.8( \pm 1.7)$ brightness values. Compared to native genotypes, brightness values were: red $35.9( \pm 1.5)$, orange $44.2( \pm 1.5)$, yellow $46.6( \pm 2.2)$, and purple 33.5 ( \pm $0.8)$.

Although brightness was originally associated with a cutin deficiency (Shi et al., 2013) it could also be attributed to alterations in the fruit cuticle. Petit et al. (2014) found that mutant tomato fruits with altered brightness levels displayed variations in cutin abundance and composition, in addition to disruptions in epidermal patterning. For the native genotypes analyzed in this study, incident light was reflected in a broad range of directions because of surface irregularities, which was likewise observed by Petit et al. (2014). In contrast, for the hybrid genotypes, a smoother surface was observed, and incident light was reflected in a mirror-like manner. Our results suggest that brightness could indirectly contribute to fruit selection, since fruits with higher brightness levels are perceived as fresher and more attractive by consumers. 


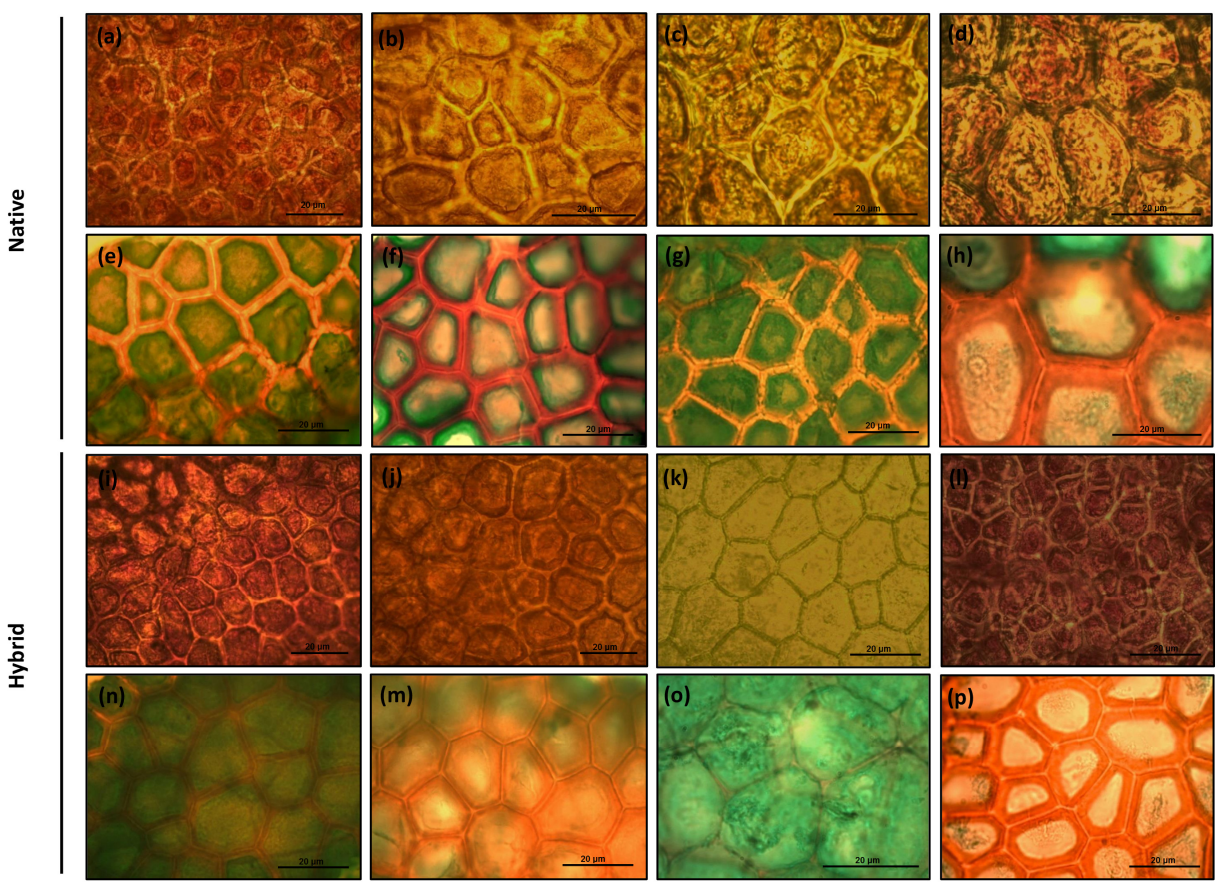

Fig. 2. Light micrographs of sections of tomato epidermis without staining (above) and stained with Safranin O- fast green (below). Red genotype (a \& e), orange (b \& f), yellow (c \& g), purple ( $\&$ \& h), light red (i \& n), light orange (j \& m), chartreuse yellow (k \& o), black (1 \& p). Scale bar: $20 \mu \mathrm{m}$

\section{Cuticle and epidermal cell wall thickness}

Optical microscopy and SEM (Figs. 4 and 5) revealed important differences in cuticle and epidermal cell wall morphology among genotypes. The cuticle was significantly thicker in native genotypes $(9.04 \mu \mathrm{m}$ on average) compared to hybrid genotypes ( $5.71 \mu \mathrm{m}$ on average), and the lighter Safranin O staining suggested a different composition. The exception was the chartreuse yellow hybrid genotype, which had the thickest cuticle. Epidermal cell wall thicknesses and areas were also higher in native genotypes (Table 1). The red native genotype showed both the largest epidermal cell areas and thicknesses $(495.2( \pm 66)$ and $4.40( \pm 0.1) \mu \mathrm{m}$, respectively; Table 1, Fig. 4). These results for cuticle thickness are in the range of those reported by Borowiak and Habdas (1988), who studied five hybrid tomato cultivars and found a thickness within the range of 0.66$4.40 \mu \mathrm{m}$.
Epidermal cell morphologies were also different among genotypes. In the cross-sections examined with optical microscopy, the epidermal cells of native genotypes were oval-shaped, while the cells of hybrid genotypes were elongated. The epidermal cells of the chartreuse yellow and light-red hybrid genotypes displayed a conical shape, while the black and light-orange genotypes had square-shaped cells (Fig. 4). Hybrid genotypes, particularly the light-red and chartreuse yellow varieties, displayed well-developed anticlinal pegs between epidermal cells, while native genotypes had short anticlinal pegs, which were present only to one-third the depth of the epidermal cells. Our results suggest that the native genotypes examined have a cuticular morphology like other related species, such as Solanum cheesmaniae, which is reported to show thin anticlinal pegs (Yeats et al., 2012). Sub-epidermal layers were also different among the genotypes (Table 1).

Table 1. Cuticle thickness, epidermal cell wall thickness and area, and anticlinal peg depth

\begin{tabular}{|c|c|c|c|c|c|c|}
\hline & Genotypes & Cuticle thickness $(\mu \mathrm{m})$ & $\begin{array}{l}\text { Epidermal cell wall } \\
\text { thickness }(\mu \mathrm{m})\end{array}$ & Epidermal cell area $(\mu \mathrm{m})$ & $\begin{array}{l}\text { Number of Sub- } \\
\text { epidermal layers }\end{array}$ & $\begin{array}{c}\text { Anticlinal peg depth } \\
(\mu \mathrm{m})\end{array}$ \\
\hline \multirow{4}{*}{$\mathrm{N}$} & $\mathrm{R}$ & $9.92( \pm 2.6) \mathrm{a}$ & $4.40( \pm 0.1) \mathrm{a}$ & $495.2( \pm 66)$ a & 2 & $3.18( \pm 1.6) \mathrm{c}$ \\
\hline & $\mathrm{O}$ & $3.55( \pm 0.7) \mathrm{b}$ & $1.01( \pm 0.1)$ e & $259.1( \pm 47) b$ & 2 & $5.65( \pm 1.2) \mathrm{c}$ \\
\hline & $\mathrm{Y}$ & $11.11( \pm 2.1) \mathrm{a}$ & $3.76( \pm 72) b$ & $303.3( \pm 105) b$ & 2 & $2.1( \pm 0.3) \mathrm{d}$ \\
\hline & $\mathrm{P}$ & $11.59( \pm 2.6) \mathrm{a}$ & $4.39( \pm 0.1) \mathrm{a}$ & $356.7( \pm 72) b$ & 3 & $3.81( \pm 0.7) \mathrm{c}$ \\
\hline \multirow{4}{*}{$\mathrm{H}$} & LR & $5.25( \pm 1.5) b$ & $2.97( \pm 0.12) c$ & $278.9( \pm 44) b$ & 3 & $12.85( \pm 2.4) \mathrm{a}$ \\
\hline & LO & $3.83( \pm 0.46) b$ & $1.68( \pm 0.41) \mathrm{d}$ & $134.7( \pm 58) \mathrm{c}$ & 3 & $1.85( \pm 0.1) \mathrm{d}$ \\
\hline & $\mathrm{C}$ & $12.6( \pm 1.9) \mathrm{a}$ & $3.92( \pm 0.24) b$ & $382.8( \pm 106) b$ & 3 & $7.5( \pm 0.9) \mathrm{b}$ \\
\hline & B & $1.2( \pm 0.1) \mathrm{c}$ & $1.04( \pm 0.1) \mathrm{e}$ & $174.9( \pm 64) \mathrm{c}$ & 2 & $3.1( \pm 0.7) \mathrm{c}$ \\
\hline
\end{tabular}

Native genotypes $(\mathrm{N})$ : red $(\mathrm{R})$, orange $(\mathrm{O})$, yellow $(\mathrm{Y})$, purple $(\mathrm{P})$. Hybrid genotypes $(\mathrm{H})$ : light red (LR), light orange (LO), chartreuse yellow $(\mathrm{C})$ and black $(\mathrm{B})$. Mean values followed by the same letter in each column are not significantly different among each other according to the Tukey's multiple comparison test $(\alpha=0.05)$. Firmness was positively correlated with a higher number of sub-epidermal layers (Pearson correlation coefficient $\mathrm{R}=0.6387$ ) 


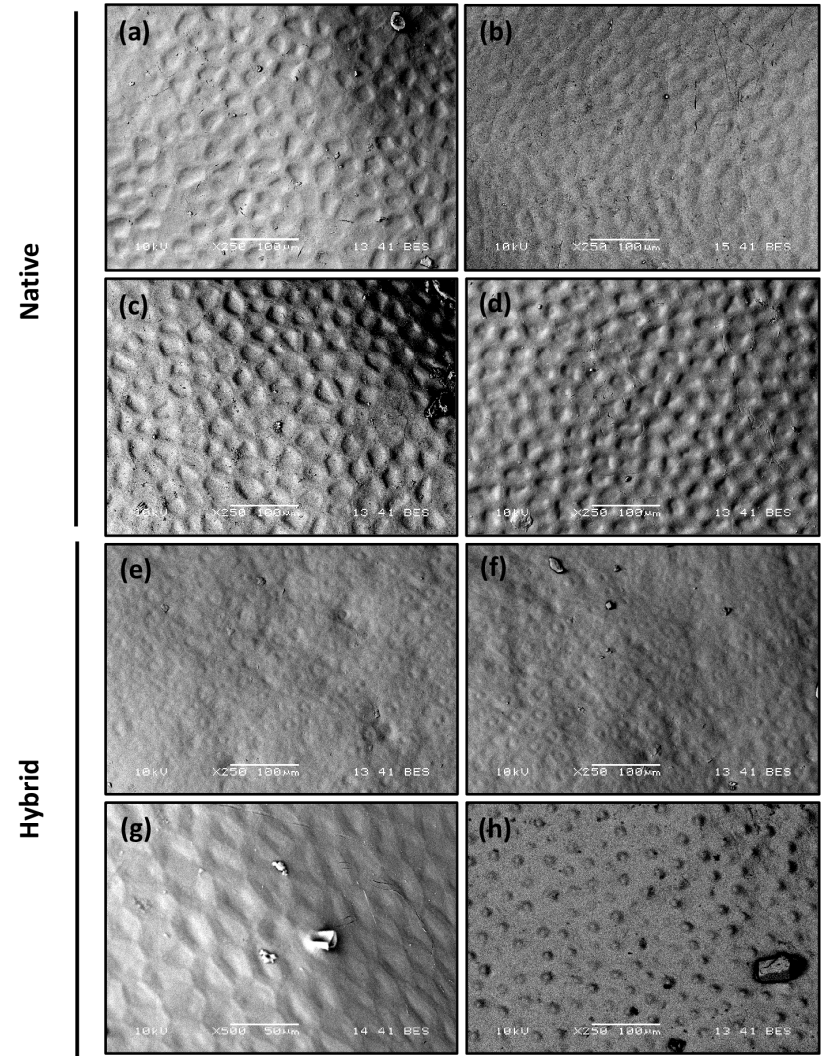

Fig. 3. Tomato surface observed by scanning electron microscopy (SEM). Red genotype (a), orange (b), yellow (c), purple (d), light red (e), light orange (f), chartreuse yellow (g), black (h). Scale bar: $100 \mu \mathrm{m}$
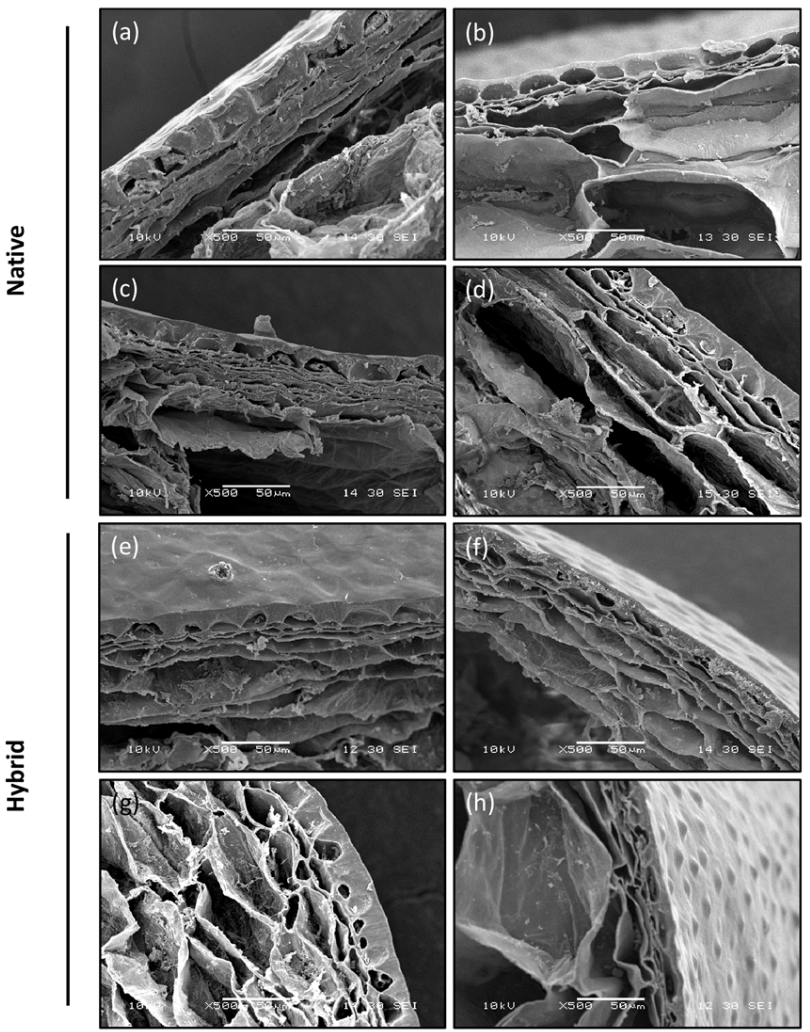

Fig. 5. Cuticular structure of tomato observed by scanning electron microscopy (SEM) of sections of tomato epidermis. Red genotype (a), orange (b), yellow (c), purple (d), light red (e), light orange (f), chartreuse yellow (g), black (h). Scale bar: $100 \mu \mathrm{m}$

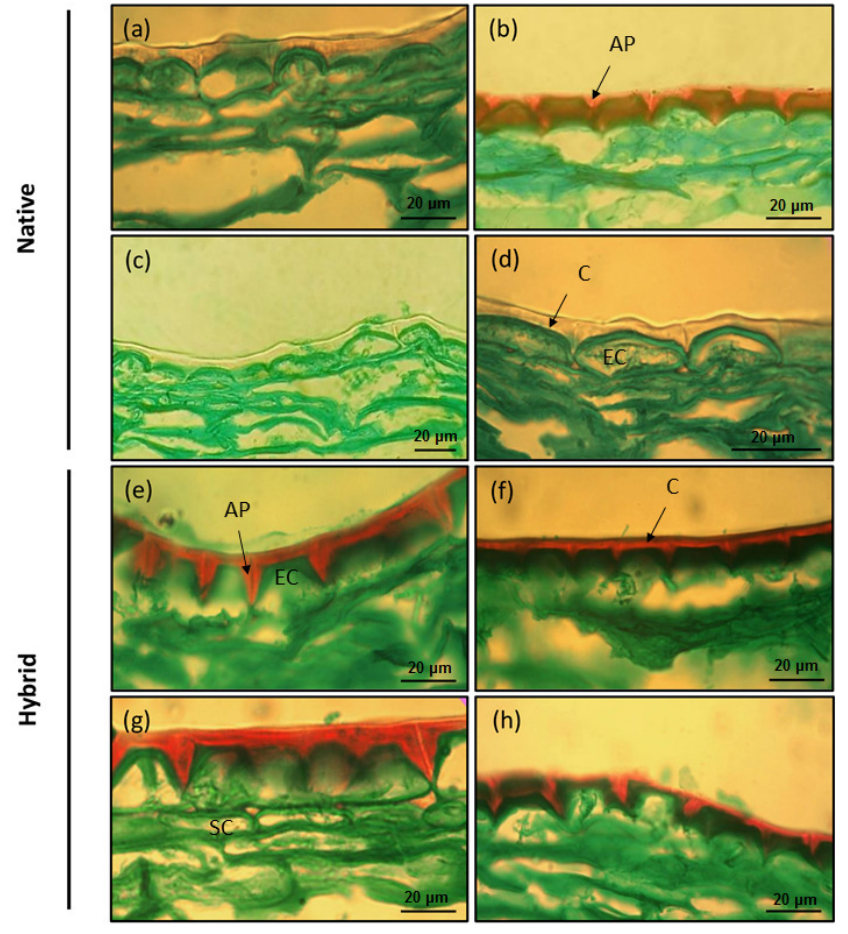

Fig. 4. Light micrographs of sections of tomato fruit stained with Safranin O (stains cutin and lignified walls) - Fast Green (stains cellulosic walls). Red genotype (a), orange (b), yellow (c), purple (d), light red (e), light orange (f), chartreuse yellow (g), black (h). (C= cuticle, $\mathrm{SC}=$ sub-epidermal cells, $\mathrm{AP}=$ anticlinal peg, $\mathrm{EC}=$ epidermal cell). Scale bar: $20 \mu \mathrm{m}$

In tomato fruits, the epicarp is formed by strongly cutinized epidermal and subepidermal or hypodermic colenchymal cells. Tomato fruits have between two and four layers of hypodermic cells that are frequently distinguished from the rest of the mesocarp because they are of smaller size and have a thickening of the wall (Cotner et al., 1969; Chu and Thompson, 1972). In this study, most of the native genotypes had only two sub-epidermal layers, while most hybrid genotypes had three layers.

A positive correlation was observed between greater firmness levels and a higher number of sub-epidermal layers $(\mathrm{R}=0.6387)$, suggesting that sub-epidermal layers of the pericarp also play an important role in fruit firmness. The morphology and mechanical performance of the exocarp, including the cuticle, the epidermis, and a variable number of hypodermal (or subepidermal) cell layers, are of considerable economic significance because they affect the integrity of the whole fruit. These factors also affect not only fruit appearance, but also handling resistance and storage behavior, and they play a prominent role in fruit cracking (Bargel and Neihuis, 2004).

\section{Firmness and cuticle thickness}

Greater firmness was observed in hybrid genotypes compared to native genotypes (Table 2). The chartreuse yellow hybrid genotype was the firmest, followed by the purple native genotype. Firmness measurements of the epidermis showed, that in native genotypes, the epidermis contributes greatly to fruit firmness. A relationship between epidermal cell area and firmness was also found, since hybrid genotypes with smaller epidermal cells showed higher firmness. Chaib et al. (2007) suggest that the pericarp of 
Table 2. Measurements of firmness, contribution to the epidermis to fruit firmness, weight loss and stem scar/ fruit diameter ratio

\begin{tabular}{|c|c|c|c|c|c|}
\hline \multicolumn{2}{|c|}{ Genotypes } & Firmness with epidermis & $\begin{array}{l}\text { Contribution of epidermis to } \\
\text { fruit firmness (\%) }\end{array}$ & Weight loss at 10 days (\%) & $\begin{array}{l}\text { Stem scar diameter/ fruit } \\
\text { diameter ratio }\end{array}$ \\
\hline \multirow{4}{*}{$\mathrm{N}$} & $\mathrm{R}$ & $2.2( \pm 1.0) \mathrm{e}$ & 55.4 & $20.5 \mathrm{a}$ & 0.19 \\
\hline & $\mathrm{O}$ & $3.63( \pm 0.5) \mathrm{d}$ & 10 & $22.9 \mathrm{a}$ & 0.14 \\
\hline & Y & $3.12( \pm 1.2) \mathrm{e}$ & 58.1 & $19.3 \mathrm{a}$ & 0.22 \\
\hline & $\mathrm{P}$ & $14.36( \pm 2.4) b$ & 13.5 & $13.6 \mathrm{~b}$ & 0.17 \\
\hline \multirow{4}{*}{$\mathrm{H}$} & LR & $10.16( \pm 1.7) \mathrm{c}$ & 6.76 & $20.8 \mathrm{a}$ & 0.18 \\
\hline & LO & $13.75( \pm 2.9) \mathrm{b}$ & 4.97 & $22.8 \mathrm{a}$ & 0.14 \\
\hline & $\mathrm{C}$ & $34.38( \pm 5.2) \mathrm{a}$ & 9.79 & $11.15 \mathrm{~b}$ & 0.21 \\
\hline & B & $13.77( \pm 2.1) \mathrm{b}$ & 0.36 & $12.0 \mathrm{~b}$ & 0.11 \\
\hline
\end{tabular}

Native genotypes $(\mathrm{N})$ : red (R), orange $(\mathrm{O})$, yellow $(\mathrm{Y})$, purple $(\mathrm{P})$. Hybrid genotypes $(\mathrm{H})$ : light red (LR), light orange (LO), chartreuse yellow (C) and black (B). Mean values followed by the same letter in each column are not significantly different among each other according to the Tukey's multiple comparison test $(\alpha=0.05)$
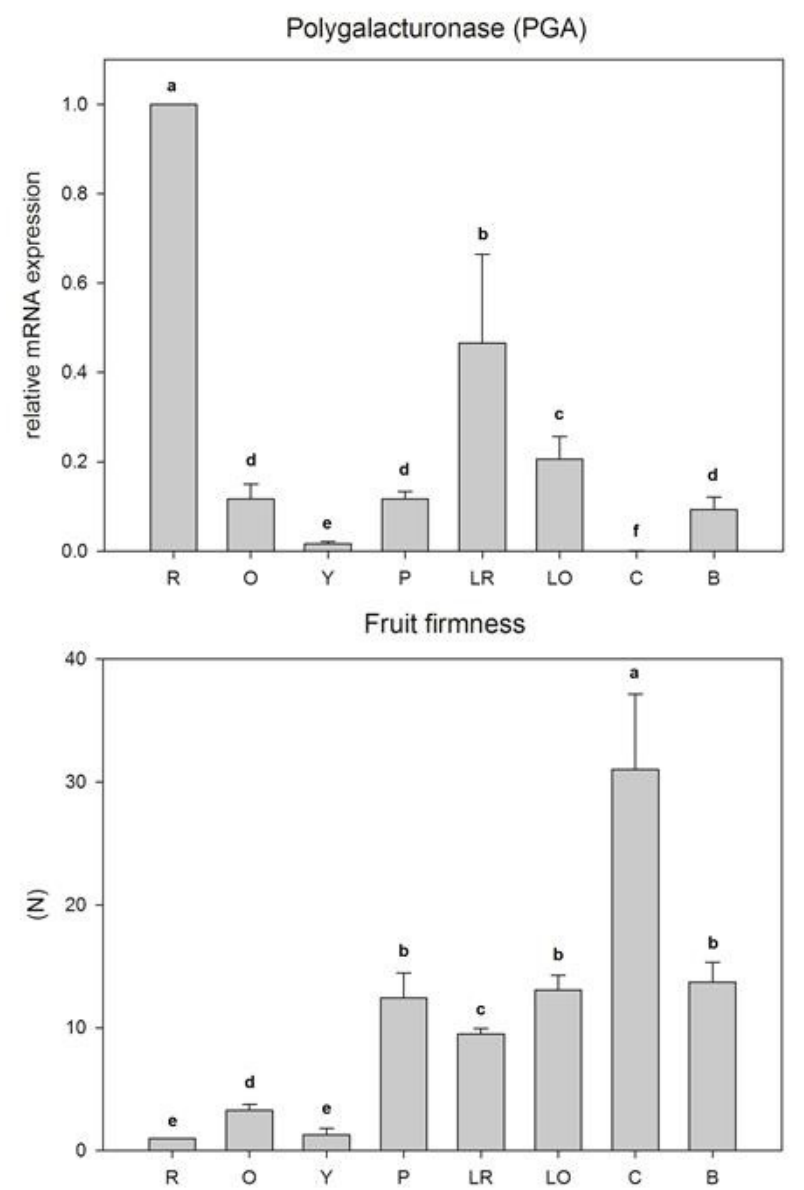

Fig. 6. Relative expression of polygalacturonase and fruit firmness. Native genotypes: red $(\mathrm{R})$, orange $(\mathrm{O})$, yellow $(\mathrm{Y})$, purple (P). Hybrid genotypes: light red (LR), light orange (LO), chartreuse yellow (C) and black (B). Mean values followed by the same letter in are not significantly different among each other according to the Tukey's multiplecomparison test $(\alpha=0.05)(n=3)$ vertical bars represent standard deviation. A negative Pearson correlation index between firmness and PGA expression $(\mathrm{R}=-0.25)$ was found

firm tomatoes is composed of small cells under the cuticle.

Firmness and PGA expression

$P G A$ expression was negatively correlated with firmness $(\mathrm{R}=-0.25$; Fig. 6). Native genotypes were fewer firms and had higher $P G A$ expression levels compared to hybrid genotypes. The chartreuse yellow genotype showed the lowest $P G A$ expression levels (relative expression of 0.0008 ), which also coincided with the highest firmness with and without the epidermis. A positive correlation between firmness and anticlinal peg depth was also found $(\mathrm{R}=$ $0.675)$, suggesting that this parameter has a direct influence on firmness.

Firmness is a trait of great commercial interest and a critical component in the perception of fruit quality (JuárezLópez et al., 2009). PGA is the major enzyme responsible for pectin disassembly during tomato fruit ripening. The activity of this enzyme alters the texture and firmness of the fruit because of the degradation of the structural components necessary to reinforce the cell wall and the adhesion of cells (Xiao et al., 2014). España et al. (2014) found a positive correlation between total phenolic content and firmness, suggesting that these compounds also contribute to the increase in stiffness of the cuticle, allowing the fruit to withstand transient changes in volume with little expansion.

\section{Weight loss and stem scar diameter}

A lower percentage of weight loss after 10 days of storage was observed for the tomato genotypes with bigger diameters (purple and chartreuse yellow) because of less exposed surface with respect to their volume (Table 2). Despite this, the black-cherry genotype had a smaller weight loss, which was similar to that of the bigger genotypes. This was probably because it had the smallest stem scar / fruit diameter ratio, which showed a positive correlation $(\mathrm{R}=$ 0.8853). It has been previously reported that most transpiration occurs through the peduncle (stem scar) and not through the cuticle (Bouzo and Gariglio, 2016). Weight loss was also negatively correlated with firmness because firmer fruits underwent less weight loss. Less weight loss is a desirable trait to select for in breeding programs because the tomato, particularly the cherry-type, is a highly perishable fruit.

\section{Conclusions}

The genotypes analyzed here exhibit a high variation in cuticle and epidermal cell morphologies. Dynamic changes in the structure and composition of the fruit cuticle lead to a reduction in fruit firmness, affecting fruit quality and subsequent commercialization. Comparative studies have been carried out for wild tomato species; however, there 
have been few reports than compare the morphology of the cuticle and epidermis among hybrid and native tomato genotypes of the same species. We showed that native genotypes had irregularly shaped epidermal cells and a thicker cuticle. Meanwhile, the surfaces of hybrid fruit were smoother and brighter in comparison, resulting in less weight loss. This correlated with a smaller stem scar diameter in these hybrid fruits compared to the native types. A negative correlation between firmness and $P G A$ transcript levels was found. The chartreuse yellow genotype showed the highest amount of firmness and the lowest $P G A$ expression levels, while the black genotype showed the smallest peduncle diameter and least amount of weight loss. Moreover, firmness was positively correlated with a higher number of sub-epidermal layers and deeper anticlinal pegs. Our results suggest that, because of the selection process, several morphological aspects of the cuticle and epidermis of tomato fruits have been altered.

\section{Acknowledgements}

The present research was developed thanks to the financial support of UAM and PRODEP. CVH holds a CONACYT scholarship (265752) for his PhD studies.

\section{References}

Bargel H, Neinhuis C (2004). Altered tomato (Lycopersicon esculentum Mill.) fruit cuticle biomechanics of a pleiotropic non-ripening mutant. Journal of Plant Growth Regulation 23(2):61-75.

Bonilla-Barrientos O, Lobato-Ortiz R, García-Zavala JJ, Cruz-Izquierdo S, Reyes-López D, Hernández-Leal E, Hernández-Bautista A (2014). Agronomic and morphological diversity of local kidney and bell peppershaped tomatoes from Puebla and Oaxaca, México. Revista Fitotecnia Mexicana 37(2):129-139.

Borowiak J, Habdas H (1988). The relationship between the anatomical structure of the tomato fruit pericarp (Lycopersicon esculentum Mill.) and its mechanical properties. Acta Agrobotanica 41(2):285-293.

Bouzo CA, Gariglio NF (2016). Relationship between different physical properties of tomato fruits and water loss during postharvest. Acta Scientiarium Polonorum Hortorum 15:13-25.

Chang S, Puryear J, Cairney J (1993). A simple and efficient method for isolating RNA from pine trees.Plant Molecular Biology Reporter 11:113-116.

Chaib J, Devaux MF, Grotte MG, Robini K, Causse M, Lahaye M, Marty I (2007). Physiological relationships among physical, sensory, and morphological attributes of texture in tomato fruits.Journal of
Experimental Botany 58(8):1915-1925.

Chu MC, Thompson AE (1972). Morphology and genetics of fleshy calyx and their relation to crack resistance in tomatoes. Journal of the American Society for Horticultural Science 97(2):197-203.

Cotner SD, Burns EE, Leeper PW (1969). Pericarp anatomy of crackresistant and susceptible tomato fruits. Journal of the American Society for Horticultural Science 94(2):136-137.

Domínguez E, Heredia-Guerrero JA, Heredia A (2011). The biophysical design of plant cuticles: an overview. New Phytologist 189(4):938-949.

España L, Heredia-Guerrero JA, Segado P, Benítez JJ, Heredia A, Domínguez (2014). Biomechanical properties of the tomato (Solanum lycopersicum) fruit cuticle during development are modulated by changes in the relative amounts of its components. New Phytologist 202(3):790802.

Heredia A, Domínguez E, Segado P (2015). Ultrastructure of the epidermal cell wall and cuticle of tomato fruit (Solanum lycopersicum L.) during development. Plant Physiology 168(3):1-18.

Juárez-López P, Castro-Brindis R, Colinas-León T, Sandoval-Villa M, Ramírez-Vallejo P, Reed DW, Cisneros-Zevallos L, King S (2009). Evaluación de calidad de siete genotipos silvestres de jitomate (Lycopersicon esculentum). Revista Chapingo Serie Horticultura 15:5-9.

Lara I, Belge B, Goulao LF (2014). The fruit cuticle as a modulator of postharvest quality. Postharvest Biology and Technology 87:103-112.

Martin LB, Rose JK (2014). There's more than one way to skin a fruit: formation and functions of fruit cuticles. Journal of Experimental Botany 65(16):4639 4651.

Petit J, Bres C, Just D, Garcia V, Mauxion JP, Marion D, Rothan, C (2014). Analyses of tomato fruit brightness mutants uncover both cutindeficient and cutin-abundant mutants and a new hypomorphic allele of GDSLlipase. Plant Physiology 164(2):888-906.

Shi JX, Adato A, Alkan N, He Y, Lashbrooke J, Matas AJ, Leshkowitz, D (2013). The tomato SISHINE3 transcription factor regulates fruit cuticle formation and epidermal patterning. New Phytologist 197(2):468-480.

Steiner, A. A. (1966). The Influence of Chemical Composition of a Nutrient Solution on the Production of Tomato Plants. Plant and Soil 24(3): 454466.

Xiao C, Somerville C, Anderson CT (2014). Polygalacturonase involved in expansion functions in cell elongation and flower development in Arabidopsis. The Plant Cell 26(3):1018-1035.

Yeats TH, Martin LB, Viart HM, Isaacson T, He Y, Zhao L, Rose JK (2012). The identification of cutin synthase: formation of the plant polyester cutin. Nature Chemical Biology 8(7):609-611. 